Case Report

\title{
MINOCYCLINE INDUCED EOSINOPHILIC PNEUMONIA: \\ CASE REPORT AND REVIEW OF LITERATURE
}

\author{
S. Klerkx, K. Pat, W. Wuyts
}

Key words: eosinophilic lung disease, minocycline

\begin{abstract}
A 51-year-old woman with eosinophilic pneumonia due to minocycline is described and a review of available literature is added. Until now, only 49 cases have been described, mainly in the Japanese population. Minocycline induced eosinophilic pneumonia is probably underreported and even underdiagnosed. This case highlights the importance of careful history taking, especially the use of drugs. Relatively safe drugs (like minocycline) can cause serious adverse events. On presentation, the disease mimics an infectious pneumonia. Peripheral eosinophilia can occur but isn't obligatory. A bronchoalveolar lavage may provide the first (and sometimes only) sign of eosinophilic lung disease. Withdrawal of minocycline is often enough although sometimes corticosteroids are needed. In general, prognosis is good when the diagnosis is made on time.
\end{abstract}

UZ Leuven,

Department of pneumology,

Herestraat 49, B-3000 Leuven

Address for Correspondence:

Prof. Dr. Wim Wuyts

UZ Leuven

Department of pneumology.

Herestraat 49

B-3000 Leuven

Tel: ++32016346801

Fax: ++2016346803

E-mail:wim.wuyts@uzleuven.be

\section{INTRODUCTION}

Minocycline induced eosinophilic pneumonia is a rare disorder but every doctor should be aware of this serious adverse event. Nowadays minocycline is often prescribed for common acne in young people. It is often forgotten in history taking because patients don't consider it as a drug. On presentation, the disease mimics an infectious pneumonia. Peripheral eosinophilia can occur but isn't obligatory. Cessation of minocycline is often enough to cure the patient, in some case corticosteroids are needed.

\section{CASE REPORT}

A 51-year-old woman with no significant medical history was admitted to our hospital with a history of dyspnea, dry cough, fever up to $39.9^{\circ} \mathrm{C}$, vomiting and myalgia since one day. Six days before admission, she started a treatment with minocycline $50 \mathrm{mg}$ twice a day for common acne.

The physical examination revealed an oxygen saturation on room air of $89 \%$ and no fever. Chest auscultation showed bilateral fine crackles.

The white blood cell count was $23.10 * 9 / \mathrm{l}$ (normal 4.0-10.0) with $90.6 \%$ of neutrophils (normal 38.077.0) and no eosinophils. The serum level of C-reactive protein was $340 \mathrm{mg} / \mathrm{l}$ (normal <5.0). Liver function tests were normal. On admission blood gas analysis with two liters of oxygen showed a pO2 of $66 \mathrm{mmHg}$, a pCO2 of $35 \mathrm{mmHg}$ and an oxygen saturation of $94 \%$. Chest X-ray showed minimal interstitial changes and chest computed tomography (CT) diffuse ground glass 
opacities, thickening of septa and mediastinal and hilar lymphadenopathy (figure 1, 2, 3).

Differential diagnosis on admission was minocycline induced pneumonia or infectious pneumonia. Minocycline was discontinued and antibiotics were added.

A bronchoscopy with bronchoalveolar lavage (BAL) was performed the day after admission. No transbron-

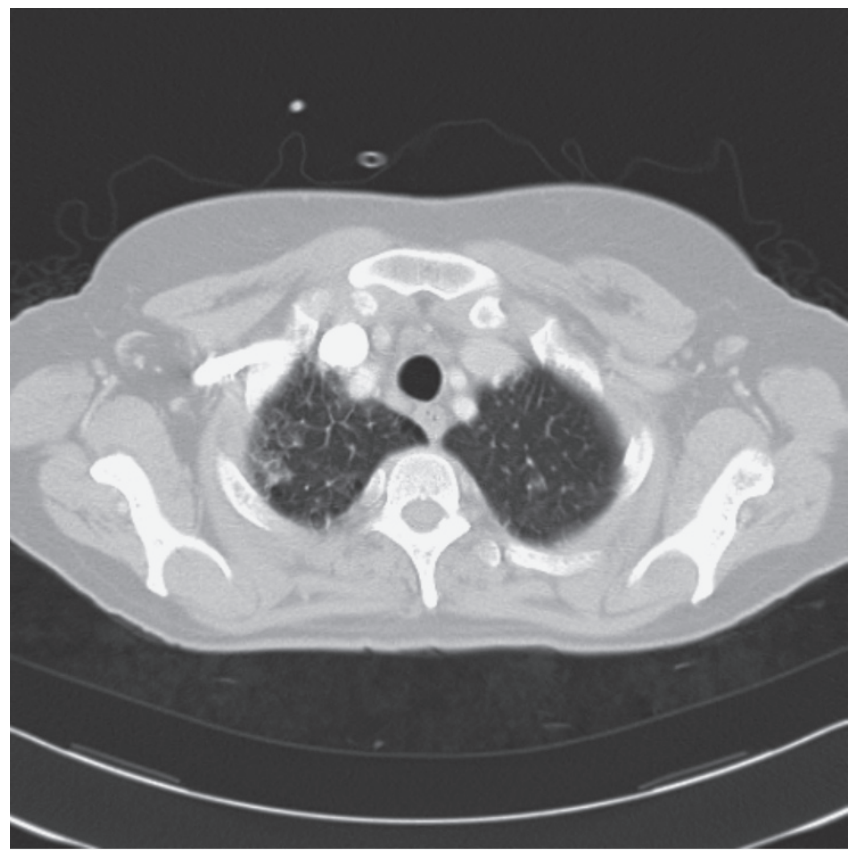

Figure 1: Mediastinal lymphadenopathy

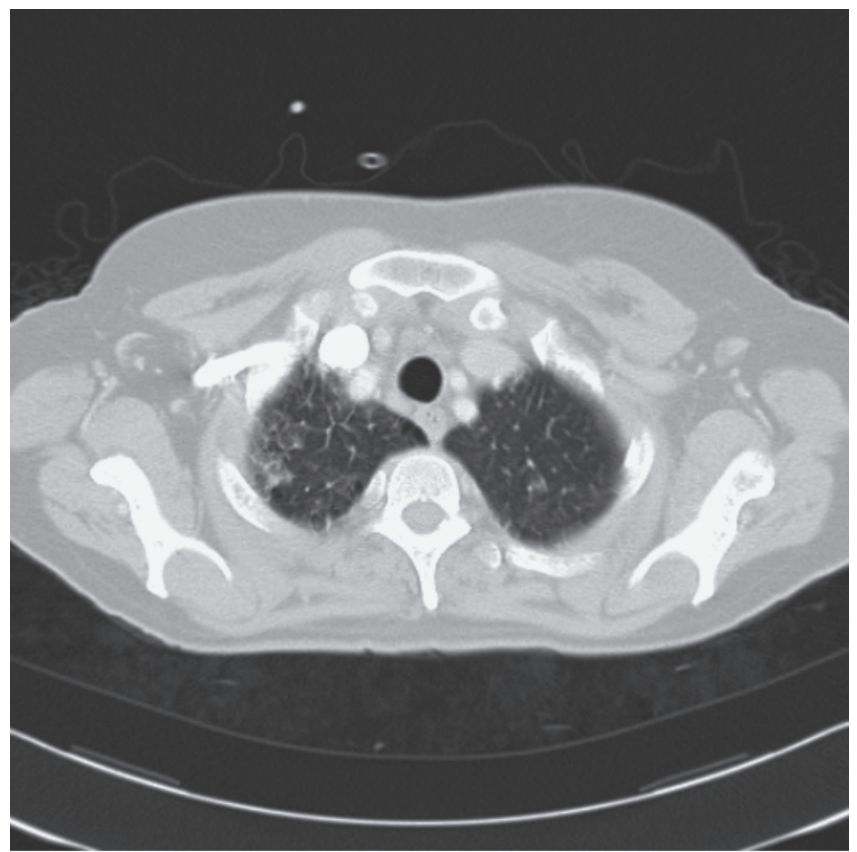

Figure 2: Ground glass opacities and thickening of interlobular septa. chial biopsies were taken. Differential cell analysis revealed a high total cell count $(246.10 * 3 / \mathrm{ml}$, normal 50-250) and 63.6\% macrophages (normal 90.0-100.0), $4.2 \%$ lymphocytes (normal $<20 \%$ ), $16 \%$ neutrophils (normal $<3.0 \%$ ) and $16 \%$ eosinophils (normal $<2 \%$ ). Culture of BAL was negative. Polymerase chain reaction for Chlamydia and Mycoplasma on BAL was negative. Urinary antigen for Legionella pneumonia was also negative.

Because of the clinical presentation, the elevated eosinophilia on BAL and no signs of infection, we concluded that this case was a minocycline induced eosinophilic pneumonia. On the third day of admission she became afebrile, biochemistry on day four showed a significant decline in inflammatory parameters, cough and dyspnea disappeared after one week.

\section{DISCUSSION}

\section{Eosinophilic lung diseases}

Eosinophilic lung diseases are a diverse group of pulmonary disorders characterized by pulmonary opacities associated with peripheral eosinophilia, tissue eosinophilia confirmed at biopsy or increased eosinophils in BAL (1). They are classified as eosinophilic lung disease of unknown cause, of known cause and eosinophilic vasculitis (table 1 ).

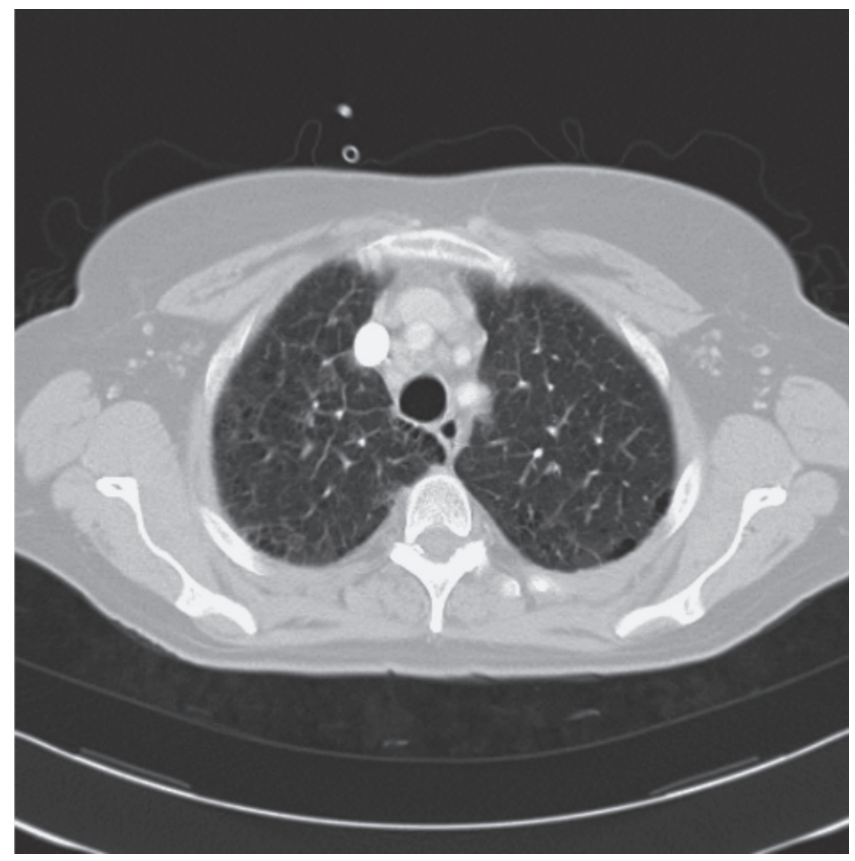

Figure 3: Thickening of interlobular septa 
Table 1

\begin{tabular}{lll}
\hline Eosinophilic lung disease of unknown cause & Eosinophilic lung disease of known cause & Eosinophilic vasculitis \\
\hline Simple pulmonary eosinophilia & Allergic bronchopulmonary aspergillosis & Churg-Strauss syndrome \\
\hline Acute eosinophilic pneumonia & Bronchocentric granulomatosis & \\
\hline Chronic eosinophilic pneumonia & Parasitic infections \\
\hline Idiopathic hypereosinophilic syndrome & Drugs and toxic substance reactions & \\
\hline
\end{tabular}

History taking is an extremely valuable diagnostic tool, in particular for eosinophilic lung disease of known cause. A history of asthma may raise suspicion of allergic bronchopulmonary aspergillosis, ChurgStrauss syndrome, bronchocentric granulomatosis or

\section{Table 2}

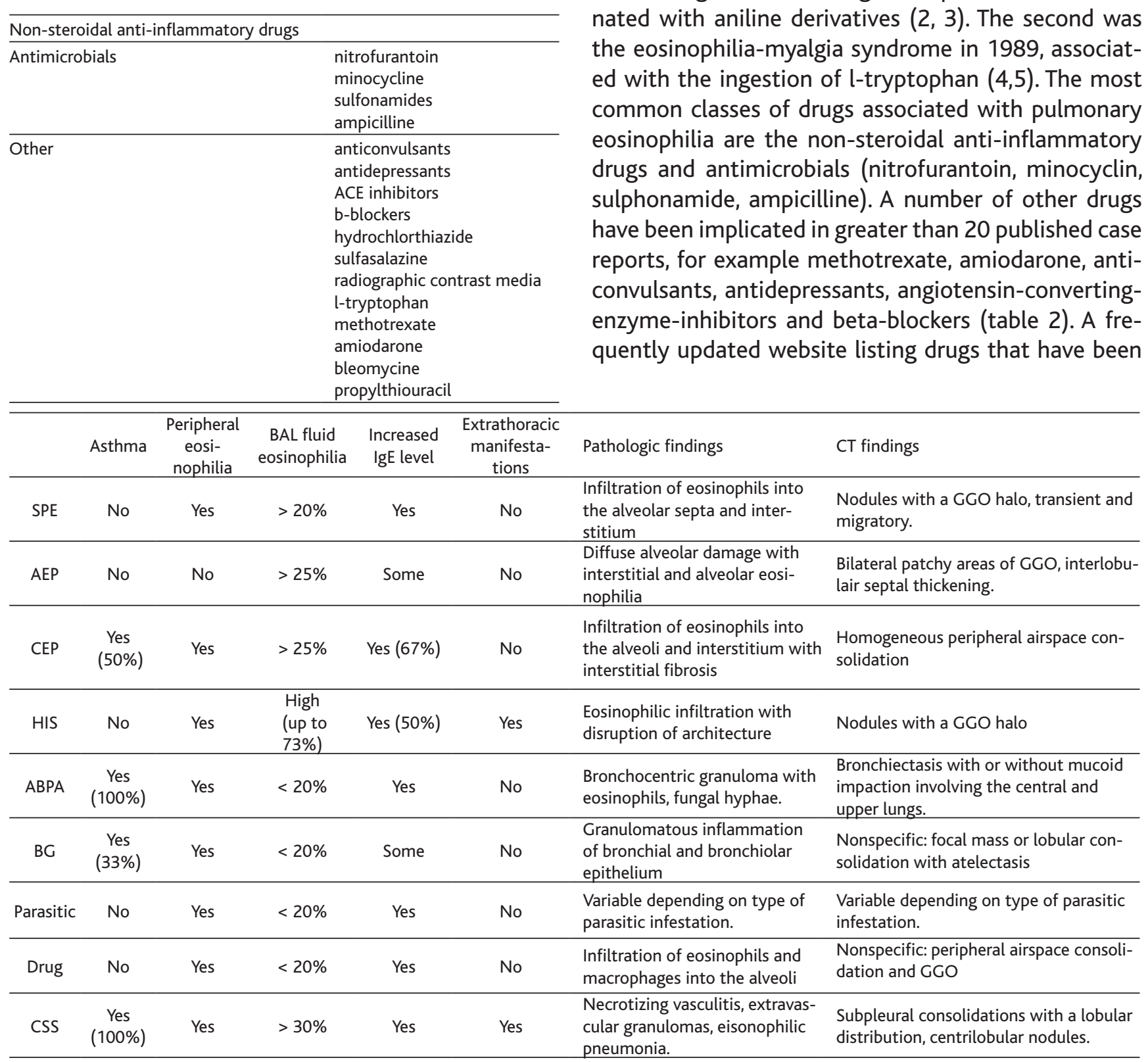

chronic eosinophilic pneumonia. Recent travelling may suggest parasitic infections and an extensive history to rule out the use of drugs is important. A wide variety of drugs and toxic substances may induce eosinophilic disease. In the past two significant outbreaks have been reported. The first is toxic-oil syndrome, affecting $>20000$ people in Spain in 1981, associated with the oral ingestion of food-grade rapeseed oil contaminated with aniline derivatives $(2,3)$. The second was the eosinophilia-myalgia syndrome in 1989 , associated with the ingestion of l-tryptophan $(4,5)$. The most common classes of drugs associated with pulmonary eosinophilia are the non-steroidal anti-inflammatory drugs and antimicrobials (nitrofurantoin, minocyclin, sulphonamide, ampicilline). A number of other drugs enzyme-inhibitors and beta-blockers (table 2) A frequently updated website listing drugs that have been

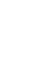


associated with pulmonary infiltrates and eosinophilia is being maintained by 'Les Groupes d'Etudes de la Pathologie Pulmonaire latrogène' $(6$, www.pneumotox. com).

A white blood cell differential cell count is an essential part in diagnosis although peripheral eosinophilia isn't necessary. BAL may provide the first (and perhaps, the only) indication of an eosinophilic lung disease. Normal BAL fluid consists of less than $1 \%$ eosinophils. Eosinophilic lung diseases of unknown cause in general have a higher BAL fluid eosinophil level than eosinophilic lung diseases of known cause (table 3).

Nonspecific findings may be seen at conventional chest radiography. CT chest often shows more characteristic patterns but there is still a considerable overlap among the eosinophilic lung diseases $(7,8$, table 3$)$.

\section{Minocycline}

Minocycline hydrochloride is a long-acting semisynthetic tetracycline derivative.

In the past it has been frequently used in the treatment of respiratory and urinary tract infections. Nowadays it's often prescribed by general practitioners and dermatologists for acne vulgaris in young people. Patients themselves do not always consider it as a real drug. Therefore it is often forgotten in history taking.

Minocycline is contra-indicated in pregnant woman because of reported congenital abnormalities (shorthening of limbs) and in children under eight year because of the tooth discoloration that can occur during tooth development.

Adverse reactions of tetracyclines are light-headedness, various rashes, headache, nausea and photosensitivity. Specific minocycline associated and often more severe adverse reactions are hyperpigmentation, hypersensitivity reactions (hypersensitivity syndrome reaction (HSR), serumsickness like syndrome (SSLS) and eosinophilic pneumonia) and autoimmune reactions (drug induced lupus, autoimmune hepatitis).

Hyperpigmentation is not only seen on skin but also on oral mucosa, nails, bone, teeth, sclerae, thyroid gland and hearth valves. Even black galactorhea is re-

\section{Table 3}

Note: SPE: simple pulmonary eosinophilia, AEP: acute eosinophilic pneumonia, CEP:

chronic eosinophilic pneumonia, IHS: idiopathic hypereosinophilic syndrome, ABPA: allergic bronchopulmonary aspergillosis, BG: bronchocentric granulomatosis, CSS: Churg-Strauss syndrome, GGO: ground glass opacity. ported. In some cases hyperpigmentation can diminish after cessation of minocycline (9).

Hypersensitivity reactions occur early in treatment, within weeks after starting the treatment. In HSR the patient develops fever and skin abnormalities (erythema, exfoliative dermatitis, exanthema or pustulous dermatitis), followed by internal damage. The liver is often involved, although damage to kidneys, heart and lung is described (9). SSLS is characterised by urticaria, fever, arthralgia and lymphadenopathy, in the absence of circulating antibodies (9). Eosinophilic pneumonia is discussed in the next paragraph.

Autoimmune reactions occur, in contrast to hypersensitivity reactions, after a longer period of treatment. In general, Minocycline induced lupus develops after 2 years of treatment $(10,11,12)$. The symptoms are (poly)arthritis, (poly)arthralgia, morning stiffness, fever and fatigue. A blood exam shows a positive antinuclear antibody titer. Minocycline induced lupus can be accompagnied by liver function abnormalities. Autoimmune hepatitis is seen in patients without minocycline induced lupus (13).

In relation to the number of prescriptions the number of serious adverse events of minocycline described is small but every doctor should be aware of them.

\section{Minocycline induced eosinophilic lung disease}

Pneumonitis due to minocycline was first reported by $\mathrm{Ho}$ et al in 1979 (14). Since then only a further 49 cases of reversible minocycline-related pneumonitis have been described. In only five articles more than one case is described $(15,16,17,18,19)$. Minocyclineinduced eosinophilic pneumonia is probably underreported, and even underdiagnosed.

The pathogenesis is unknown. Guillon et al reported cytotoxic CD8+ T lymphocyte-mediated specific cytotoxicity against minocycline-bearing alveolar macrophages in vitro (20). They hypothesized that $\mathrm{T}$ lymphocytes play a central role in the pathogenesis. However, their findings do not explain pulmonary eosinophilia, a characteristic feature of minocycline-induced pneumonitis.

On presentation minocycline induced pneumonia mimics an infectious pneumonia with high fever, dry cough and dyspnea as most frequent symptoms. Chest auscultation often reveals bilateral fine crackles. In $85 \%$ of the reported cases the symptoms presented within two weeks after the start of minocycline therapy. In general, biochemistry on admission reveals an elevated CRP, a leucocytosis with neutrophilia and often 
an eosinophilia. Review of available literature showed eosinophilia in 18/26 cases, proving it isn't an obligate sign, as was the case in our patient. Blood gas analysis often reveals severe hypoxemia.

Chest X-ray shows an (often bilateral) infiltrate(s) and sometimes a pleural effusion $(21,22,23,24)$ or mediastinal/hilar lymphadenopathy (23) but can be normal.

Bronchoalveolar lavage is important in diagnosis and most frequently shows an eosinophilic formula (16/20 reported cases) but a neutrophilic/lymfocytic formula can also occur. When transbronchial biopsies are taken or an open lung biopsy is performed, further anatomopathological examination shows elevated eosinophils but there is no pathognomonic pattern. The role of a lymphocyte stimulation test is debated. In literature we only found a positive result in 1/14 cases (25). A Japanese study of seven patients showed a negative result in $6 / 7$ patients (19). For that reason, we dit not perform a lymphocyte stimulation test in our patient.

The prognosis after withdrawal of the drug is good. No mortality has been reported. However severe transient respiratory failure necessitating ventilatory support has been described $(26,27)$ and corticosteroid therapy was required to control symptoms in several cases (13/29 reported cases). There are no guidelines to decide whether corticosteroids should be added or not.

Rechallenge is the ultimate test to proof the relationship between minocycline and the clinical presentation. We didn't perform a rechallenge because of the high risk of recurrence in contrast with the few specific indications for minocycline in treatment of infections.

\section{CONCLUSION}

Minocycline-induced eosinophilic pneumonia is a rare disease so it stresses the importance of careful history taking, especially regarding the intake of drugs . In $85 \%$ of the reported cases the disease develops within 2 weeks after the start of minocycline therapy. On presentation, it mimics an infectious pneumonia. Peripheral eosinophilia can occur but isn't obligatory. A bronchoalveolar lavage may provide the first (and sometimes only) sign of eosinophilic lung disease. Prognosis is good when the diagnosis is made on time. Cessation of minocycline is often enough, sometimes corticosteroids are needed.

\section{REFERENCES}

1. Allen JN, Davis WB. Eosinophilic lung diseases. Am J Respir Crit Care Med 1994; 150: 1423-1438.

2. Kilbourne EM, Rigau-Perez JG, Heath CW Jr, Zack MM, Falk H, Martin-Marcos M, de Carlos A. Clinical epidemiology of toxic-oil syndrome: manifestations of a new illness. N Eng J Med 1983; 309: 1408-1414.

3. Alonso-Ruiz, A, Calabozo, M, Perez-Ruiz, F, Mancebo, L. Toxic oil syndrome. A long-term follow-up of a cohort of 332 patients. Medicine (Baltimore) 1993; 72: 285.

4. Silver RM, Heyes MP, Maize JC, Quearry B, Vionnet-Fuasset M, Sternberg EM. Scleroderma, fasciitis, and eosinophilia associated with the ingestion of tryptophan. N Eng J Med 1990; 322: 874-881.

5. Swygert LA, Maes EF, Sewell et al. Eosinophilia-myalgia syndrome. Results of a national surveillance. JAMA 1990; 264: 1698.

6. Foucher P, Camus P. Pneumotox online : the drug-induced lung diseases. www.pneumotox.com. Date last accessed :August 14, 2008.

7. Johkoh T, Muller NL, Akira M, et al. Eosinophilic lung diseases : diagnostic accuracy of thin-section CT in 111 patients. Radiology 2000;216:773-780.

8. Jeong YJ, Kim KI, Seo IJ, Lee CH, Lee KN, Kim KN, Kim JS, Kwon WJ. Eosinophilic lung diseases: a clinical, radiologic, and pathologic overview. Radiographics 2007; 27: 617-638.

9. Hoefnagel JJ, Van Leeuwen RL, Mattie H et al. Bijwerkingen van minocycline in de behandeling van acne vulgaris. Ned Tijdschr Geneesk 1997; 141: 1424-1427.

10. Christodoulou CS, Emmanuel T, Ray RA, Good RA, Schnapf BM, Cawkwell GD. Respiratory distress due to minocycline-induced pulmonary lupus. Chest 1999; 115: 1471-1473.

11. Matsuura T, Shimizu Y, Fujimoto $H$, et al. Minocycline-related lupus. Lancet $1992 ; 340: 1553$.

12. Masson C, Pascaretti C, Capon F, et al. Mminocyclne-related lupus : a review of 23 defenite cases (abstract). Arthritis Rheum 196; 39(suppl): 69.

13. Rikken NET, Klinkhamer PJJM, Haak HR. Interstitial pneumonia and hepatitis caused by minocycline. The Netherlands Journal of Medicine 2004; 62: 62-64.

14. Ho D, Tashkin DP, Bein ME, Sharma O. Chest 1979; 76(1): 33-36.

15. Shintani H, Minami S, Iwabuchi K, Johkaji Y, Hashimoto A, Noumi I, Fujimura M, Matsuda T, Kitagawa M. Three cases of minocycline-induced pneumonitis. Nihon Kyobu Shikkan Gakkai Zasshi 1991; 29(6): 718-723.

16. Horikx PE, Gooszen HC. Minocycline as a cause of acute eosinophilic pneumonia. Ned Tijdschr Geneeskd 1992; 136(11): 530-532.

17. Sitbon O, Bidel N, Dussopt C, Azarian R, Braud ML, Lebargy F, Fourme T, de Blay F, Piard F, Camus P. Minocycline pneumonitis and eosinophilia. A report on eight patients. Arch Intern Med 1994; 154 (14).

18. Dykhuizen RS, Zaidi AM, Godden DJ, Jegarajah S, Legge JS. Lesson of the week: minocycline and pulmonary eosinophilia. BMJ 1995; 310: 1520-1521.

19. Toyoshima M, Sato A, Hayakawa H, Taniguchi M, Imokawa S, Chida K. A clinical study of minocycline-induced pneumonitis. Int Med 1996; 35: 176-179.

20. Guillon JM, Joly P. Autran B, et al. Minocycline induced cell mediated hypersensitivity pneumonitis. Ann Intern Med 117: 476, 1992 
21. Osanai S, Fukuzawa J, Akiba Y, Ishida S, Nakano H, Matsumoto $\mathrm{H}$, Onodera S. Minocycline-induced pneumonia and pleurisya case report. Nihon Kyobu Shikkan Gakkai Zasshi 1992; 30(2): 322-327.

22. Wolthuis A, Nackaerts K, Guffens T, Jousten T, Demedts M. Minocycline-geassocieerde pulmonale infiltraten en eosinofilie. Acta Clin Belg 2003 ; 58-1.

23. Bando T, Fujimura M, Noda Y, Hirose J, Ohta G, Matsuda T. Minocycline-induced pneumonitis with bilateral hilar lymphadenopathy and pleural effusion. Int Med 1994; 33: 177-179.

24. Arai $S$, Shinohara $Y$, Kato $Y$, Hirano S, Yoshizawa A, Hojyo M, Kobayashi N, Sugiyama H, Kudo K. A case of minocycline-induced pneumonitis with bilateral pleura effusion. Arerugi 2007; 56(10): 1293-1297.
25. Nakano K, Gemma H. Ono T, Ito I, Chida K, Nakamura H. A case of minocycline-induced eosinophilic pneumonia presenting with multiple white eosinophilic plaques in the tracheobronchial mucosa. Nihon Kokyuki Gakkai Zasshi 2001; 39(1): 24-29.

26. Kondo H, Fujita J, Inoue T, Horiuchi N, Nakao K, Iwata M, Haba $\mathrm{R}$, Ohtsuki Y. Minocycline-induced pneumonitis presenting as multiple ring-shaped opacities on chest $\mathrm{CT}$, pathologically diagnosed bronchiolitis obliterans organizing pneumonia. Nihon Kokyuki Gakkai Zasshi 2001; 29(3): 215-219.

27. Oddo M, Liaudet L, Lepori M, Broccard AF, Schaller M. Relapsing acute respiratory failure induced by minocycline. Chest 2003; 123: $2146-2148$ 